http://dx.doi.org/10.4314/gjl.v9i2.3

\title{
DEFINITENESS IN CHIYAO
}

\author{
Julius Taji
}

\begin{abstract}
The aim of this paper is to examine the linguistic devices used to express definiteness in Chiyao, a Bantu language of Southern Tanzania, Southern Malawi, and north-western Mozambique. The analysis is guided by the familiarity theory of definiteness, and is based on the data collected through audio-recording of traditional narratives which were later transcribed to identify utterances with definite NPs. Findings establish three main strategies of signalling definiteness in the language, which include morphological, morphosyntactic, and use of bare nouns. The morphological indicators of definiteness include subject and object markers while the morphosyntactic indicators include demonstratives, locative particles, possessive determiners, genitive expressions, and relative clauses. Bare definiteness is mainly expressed by nouns of inalienable possession, including those denoting body parts and family relations. These findings enrich the existing literature on definiteness in Bantu languages and inform future typological and comparative studies on this subject.
\end{abstract}

Keywords: Bantu, Chiyao, Definiteness, Familiarity theory, NP

\subsection{Introduction}

Definiteness is a grammatical category that indicates whether or not the referent of a phrase is assumed by the speaker to be identifiable to the addressee (Lambrecht, 1996). According to Lyons (1999), a definite $\mathrm{NP}^{1}$ indicates that both the speaker and hearer are aware of the entity being referred to by the NP. This suggests that, with definite NPs, there is a sense of familiarity with the referent and awareness sharing among interlocutors. There are cross-linguistic variations regarding how languages express

\footnotetext{
${ }^{1}$ In this paper, the following abbreviations have been used: 1,2,3 etc. $=$ Noun class; Assoc. $=$ Associative; CAUS = Causative , DEM = Demonstrative; DIST = Distal $;$ FUT = Future GEN = Negative/negation; IND = Indicative; INF = Infinitive LOC = Locative; NP = Noun phrase; NPP = Nominal pre-prefix; NON_PROX = Non proximal $;$ OM = Object marker; PFV = Perfective; PL = Plural; PART = Particle; PROX = Proximal PST = Past SG = Singular; POSS = Possessive PRS = Present SM = Subject marker.
} 
definiteness. However, the most common ways include use of definite and indefinite articles such as the English articles the and $a$, use of affixes, and use of other determiners such as possessives and demonstratives (Lambrecht, 1996; Lyons, 1999). In addition to these, a significant number of languages employ word order, numerals, and case-marking particles as strategies to express definiteness (Lambrecht, 1996).

In Bantu languages, various methods of expressing definiteness have been reported. Among such methods include the use of nominal pre-prefix (NPP) as in Dzamba (Bokamba, 1971) and Bemba (Givón, 1978); modification by a relative clause, as in Dzamba (Bokamba, 1971); use of demonstratives, as in Northern Sotho (Mojapelo, 2007); use of object markers, as in Northern Sotho (Mojapelo, 2007) and isiXhosa (Visser, 2008); and the co-occurrence of the subject marker and the nominal pre-prefix, as in Runyankore-Rukiga (Asiimwe, 2014).

This paper seeks to enrich the existing literature on definiteness in Bantu languages by discussing different strategies for expressing definiteness in Chiyao. The language under discussion, Chiyao, is a cross-border Bantu language spoken in Southern Malawi, north-western Mozambique, and Southern Tanzania. The language is classified as P21 in Guthrie's (1948) classification, and is part of the Ruvuma Bantu branch in Nurse and Philippson's (1980) classification. The next section addresses the theoretical underpinning of the study so as to provide a framework for the discussion that will follow in the subsequent sections.

\subsection{Theoretical underpinning}

The analysis in this paper is grounded on the familiarity theory of definiteness as proposed by Christophersen (1939) and further discussed by Karttunen (1968) and Heim (1982). This theory holds that definite NPs function to signal that the intended referent is already familiar to the audience at the current stage of the conversation. In this regard, in order for an NP to be interpreted as definite, the speaker and the addressee must share some knowledge of the referent. Following some scepticism as to whether every NP must have a referent, Karttunen (1968) further developed the theory to include discourse referents as among the elements that are referred to by definite NPs. Further associating definiteness with discourse, Heim (1982:195) argues that an NP is familiar in a text if it is coindexed with another NP that precedes it in the same text. The familiarity theory of definiteness is relevant to the present discussion as the discussion is based on materials from narrative discourse. The Chiyao extract in (1) below illustrates the idea of familiarity as a prerequisite for definiteness. 


\begin{tabular}{lllll}
\hline (1) Va-a-pali & bwana na bibi kalakala & ko. \\
2-PST-exist & 9.husband and & 9.wife & past & DEM. \\
Va-temi-nji & pa-nga-pata & mw-anache & \\
2SM-stay.PST-PL 16LOC-NEG-get & 1-child & \\
'There was a husband and wife in the past. They stayed without getting a child.'
\end{tabular}

In the first sentence in (1) above, the narrator introduces the characters through the NP bwana na bibi 'husband and wife.' This NP is new to the addressee since it has never been mentioned before and thus it is indefinite. But in the second sentence, the NP is not fully mentioned; instead, it is coindexed through a subject marker $v a$-. This is because at this stage, both the speaker and the addressee have some knowledge of the referent. The referent of the subject marker $v a$ - in the second sentence is therefore definite since both interlocutors are already familiar with it at the stage it is mentioned.

In the next section, I present a brief review of the strategies for expressing definiteness in some selected Bantu languages before narrowing the discussion to focus on Chiyao in the subsequent sections. The aim is to bring to light the common methods of expressing definiteness among Bantu languages and later on determine how Chiyao conforms to or diverges from these methods.

\subsection{Definiteness in Bantu}

The expression of definiteness in Bantu languages generally conforms to Lyons' (1999) proposed strategies for expressing definiteness employed by different languages of the world. The methods include morphological, morphosyntactic and discourse pragmatic. Morphological expression of definiteness involves the use of morphological markers (affixes) which are attached either to nouns or to verbs to coindex definite NPs. The most common of these definiteness markers in Bantu languages are nominal preprefixes as well as subject and object markers. The use of pre-prefixes to indicate definiteness has been observed in Dzamba (Bokamba, 1971) and Bemba (Givón, 1978). The examples below are from Dzamba (Bokamba, 1971).

(2) a. bá-tò

2-person

'People'

b. bà-bá-tò

NPP-2-person

'The people' (Bokamba, 1971:218). 
The presence of the nominal pre-prefix bà- in the noun bàbátò 'the people' in (2b) induces a definite and specific reading while its absence in the noun bátò 'people' in (2a) leads to an indefinite interpretation.

The morphological expression of definiteness through object markers has been recorded in isiXhosa (Visser, 2008) and Runyankore-Rukiga (Asiimwe, 2014). In Both languages, the co-occurrence of an object marker in the verb and a pre-prefix in the object NP signals definiteness. Visser (2008) offers the following examples from isiXhosa.

(3) a.

$\begin{array}{lll}\text { ii-ntombi } & \text { a-zi-hlamb-i } & \text { ngubo } \\ \text { NPP-9.girl } & \text { NEG-10SM-wash-NEG } & \text { 9.blanket } \\ \text { '(The) girls do not wash (any) blanket.' } & \end{array}$

$\begin{array}{llll}\text { b. } & \text { i i-ntombi } & \text { a-zi-yi-hlamb-i } & \text { i-ngubo } \\ & \text { NPP-9.girl } & \text { NEG-10SM-OM-wash-NEG } & \text { NPP-9.blanket }\end{array}$

'(The) girls do not wash the (specific) blanket.' (Visser, 2008:17)

Therefore, the object NP ngubo 'blanket' in (3a) has an indefinite and unspecific reading due to absence of an object marker and object pre-prefix while its counterpart ingubo in (3b) has definite and specific reading due to co-occurrence of the object marker and object pre-prefix.

Some Bantu languages express definiteness morphosyntactically. This involves modification of a noun by a nominal dependent such as a relative clause, a quantifier, a demonstrative or a possessive. A noun phrase containing such modifiers is considered familiar to the hearer. Some examples of Bantu languages in which definiteness is signalled by morphosyntactic devices include Dzamba (Bokamba, 1971) which uses relative clauses, and Northern Sotho and Runyankore-Rukiga, which both use demonstratives (Mojapelo, 2007; Asiimwe, 2014). Asiimwe (2014:201) offers the following examples from Runyankore-Rukigain in which demonstratives are used to express definiteness.

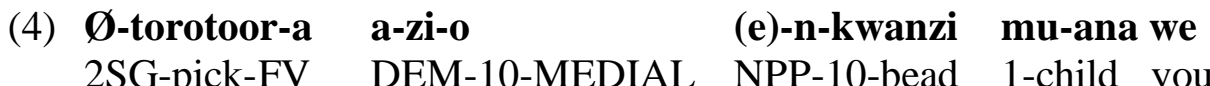
'Pick up those beads you child.'

(5) A-gi-o Ø-gaari mu-gi-taa(h)-sy-e o-mu n-ju DEM-9-MEDIAL 9-bicycle 2PL-9-enter-CAUS-IMP NPP-18.in 9-house '(You) take that bicycle in the house.'

(Asiimwe, 2014:201) 
Referents modified by demonstratives are inherently definite as the hearer can easily identify them. Thus, in the above examples, the demonstratives azio 'those' (4) and agio 'that' (5) are used to locate the referent within the environment of the speaker and hearer. The demonstratives indicate that the hearer can locate and identify the referent and thus it is definite.

Lastly, as Lyons (1999) observed, languages also express definiteness through discourse-pragmatic devices. In this type of definiteness, the hearer identifies the referent by relying on some discourse clues, for example its earlier mention in the preceding sentence of the same paragraph or conversation. In example (6) below, which is a repetition of (1), the NP bwana na bibi 'husband and wife', which appears in the first sentence is co-referenced with a subject marker $v a$-in the second sentence. The speaker replaces the full NP with the subject marker in the second sentence because it has been mentioned in the preceding discourse and therefore he/she assumes that the addressee is already aware of it.

\section{(6) Va-a-pali bwana na bibi kalakala ko. Va-temi-nji 2-PST-exist 9.husband and 9.wife past DEM. 2SM-stay.PST-PL pa-nga-pata mw-anache 16LOC-NEG-get 1-child}

'There was a husband and wife in the past. They stayed without getting a child.'

In addition to the above methods which are based on Lyons (1999), the literature also suggests that word order can induce definite and indefinite readings in Bantu languages. Duarte (2011) observed that, in Changana, when the object is moved to a topic position, it must be preceded by a definite particle $a$, which results in a definite interpretation (7b). On the other hand, when the object is in situ, it is interpreted as indefinite and the definite particle does not occur $(7 \mathrm{a})$.

$$
\begin{array}{lll}
\text { a. Maria a-fundha- } \varnothing & \text { xitchangani } \\
\text { Mary } & \text { 1SM-study-PRES } & \text { Changana } \\
\text { 'Mary studies Changana.' } & \\
\text { b. } & \begin{array}{l}
\text { a xitchanganii Maria } \\
\text { DEF Changana }
\end{array} & \text { a-fundha- } \varnothing \\
\text { 'Changana, Mary studies.' } & \text { 1SM-study-PRES }
\end{array}
$$

(Duarte, 2011:83)

These examples suggest that in Changana, topicalized elements are interpreted as old information and therefore definite. This analysis is in compliance with the view that in Bantu languages, VP-internal material tend to be interpreted as new information 
or focus while preverbal elements (topics) are interpreted as old information (see Bokamba, 1976, 1979; Bresnan \& Mchombo, 1987; Machobane, 1987; Demuth \& Mmusi, 1997; Demuth \& Harford, 1999).

The influence of word order on definiteness is also operational in Swahili. Kimambo (2018) argues that in Swahili, the canonical SVO word order can be altered to signal definiteness. In this regard, the topicalized object receives a definite interpretation just like in Changana, as illustrated in (8) below:

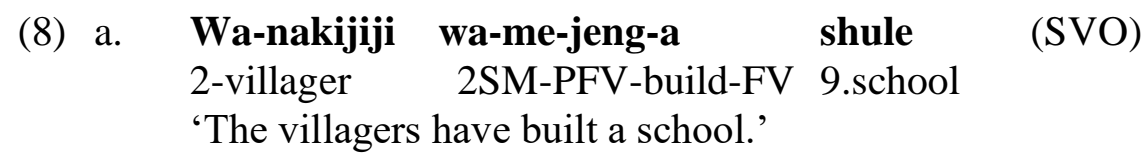
b. Shule, wa-me-i-jeng-a wa-nakijiji (OVS) 9.school 2SM-PFV-OM-build-FV 2-villager 'The villagers have built the school.' (Kimambo, 2018:76)

Thus, the topicalized NP shule 'school' in ( $8 \mathrm{~b})$ above is associated with given information, definiteness and emphasis, thus concurring with proposals by Allen (1983) and Zerbian (2007) that the topic position induces a definite reading.

Lastly, definiteness can be expressed covertly, based on the nature of the noun. Nouns that exhibit this type of definiteness are unmarked, and they include nouns with a unique characteristic such as the sun, the moon, and the world. In Runyankore Rukiga, for example, the noun omukazi 'woman' is considered unique and therefore definite (Asiimwe, 2014). Similarly, nouns of inalienable possessions such as body parts, and nouns of intimate relations are definite.

The discussion in the preceding section suggests that while there are crosslinguistic methods of expressing definiteness such as the ones proposed by Lyons (1999), individual languages display significant variations in terms of the extent to which these methods are employed. Some languages would have one dominant strategy while others would have several depending on the discourse type. Given this situation, it is insightful to explore how Chiyao expresses definiteness.

\subsection{Strategies for marking definiteness in Chiyao}

Chiyao employs a wide range of linguistic devices to express definiteness of the NP. They include morphological (through subject and object markers), morphosyntactic (through nominal dependents such as demonstratives and possessives), as well as the use of bare nouns (where the noun is neither morphologically marked nor syntactically modified). These strategies are the focus of the present section. 
4.1 Morphological expression of definiteness

Morphological expression of definiteness in Chiyao is achieved through subject and object markers which are affixed to verb stems to coindex the definite NPs. Each of these strategies is discussed below.

\subsubsection{Subject markers}

In situations where the subject NP has not been lexically expressed, the subject marker can function to indicate definiteness if the subject was mentioned previously in the same discourse. Thus, in null subject constructions, the subject marker coindexes a referent which is already known to the hearer and thus definite. In this regard, the subject marker is also used to avoid repetition of the subject as the hearer is already aware of it. The Chiyao example below is illustrative of this strategy.

$\begin{array}{llll}\text { A-sungula, } & \text { a-tati vao } & \text { nga-ni-va-ulaga. } & \text { A-jile } \\ \text { 1a-hare } & \text { 1a-father his } & \text { NEG-PST-OM-kill. } & \text { 1aSM-go.PST } \\ \text { kw-a-sisa } & \text { mu-mbugu } & \\ \text { INF-OM-hide } & \text { 18LOC-cave } & \\ \text { 'The hare did not kill his father. He went to hide him inside a cave.' }\end{array}$

In (9), the subject marker $a$ - in the second sentence is used anaphorically to refer to the antecedent asungula 'hare' which has been mentioned in the first sentence. Due to its mention in the first sentence, the subject is assumed to be known to the addressee and therefore definite. The subject marker $a$ - therefore coindexes the definite subject asungula 'hare' mentioned in the first sentence.

Theoretical support of the definite reading of the subject marker in (9) above can be drawn from Heim's (1982:179) notion of 'file keeping and updating'. She argues that when the speaker mentions a noun for the first time in a conversation, the addressee opens a file for that noun, and as the conversation keeps unfolding, the addressee simply updates it. Therefore, in example (9) above, upon hearing the NP asungula 'hare' in the first sentence, the addressee opens a file. But in the second sentence, the addressee simply updates his/her file by associating the subject marker $a$ - with the full NP asungula 'hare' mentioned in the first sentence. 


\subsubsection{Object markers}

Studies such as Wald (1973), and Byarushengo and Tenenbaum (1976) have reported that one of the key functions of the object marker in Bantu languages is to express definiteness. These studies establish that the presence of an object marker in the verb implies that its referent is familiar to and identifiable by the hearer. In this respect, the function of the object marker corresponds to the information structure (Seidl \& Dimitriadis, 1997). Within the information structure framework, the object marker denotes hearer-old and discourse-old information. As such, entities which denote new information are not likely to be object-marked (Seidl \& Dimitriadis, 1997). The object marker in Chiyao seems to conform to the information structure framework in that entities which the hearer is already aware of are object-marked while those which are new to the hearer are not object-marked. Therefore, an object marker is one of the indicators of definiteness in Chiyao, as illustrated in (10).

\section{(10) a. Basí ambusánga tu-jaule kw-ílkonde \\ Now friend 1SM-go.IND 17LOC-forest \\ tu-ka-u-sóse m-píngó \\ 1SM-FUT-OM-search 3-ebony \\ 'Now (my) friend, we should go to the forest to find the ebony.'}

b. Basí ambusánga tu-jaule kw-ílkonde

Now friend 1SM-go. IND 17LOC-forest

tu-ka-sóse m-píngó

1SM-FUT-search 3-ebony

'Now (my) friend, we should go to the forest to find ebony.'

In example (10a), the ebony being referred to is away from the speaker and hearer's visibility but it entails that the hearer has an idea of what the ebony looks like. This reading is triggered by the presence of the object marker that coindexes the referent mpíingó 'ebony'. In this case, the ebony is familiar to the hearer. Upon hearing the utterance in (10a), the hearer can easily recall the image of the ebony in his/her mind. On the other hand, (10b) can be uttered by a speaker to a hearer who has never seen the ebony and does not know how it looks like. The absence of the object marker in (10b) signals lack of familiarity which consequently induces indefinite interpretation.

The influence of object marking on definiteness has been attested in a number of other Bantu languages. In some languages, elements that rank high in the definiteness hierarchy such as pronouns and personal names are obligatorily object-marked (Morimoto, 2002:297). Bresnan and Moshi (1993:52) report that in Kichaga, the object 
marker is required when an object NP is an independent pronoun. This is because pronouns are inherently definite. Similarly, in Kiyaka, personal names, which are also inherently definite, take an obligatory object marker, as shown in (11) (Kidima, 1987:180).
a. Tu-n-telelé Maafú 2SM-OM-call.PST Maafú
'We called Maafú.'
b. *Tu-telelé Maafú
2SM-call.PST Maafú
Int: 'We called Maafú.'

(Kidima, 1987:180)

A similar pattern has been observed in Kihung'an (Morimoto, 2002:298) and Zulu (Wald, 1979). In both languages, the presence of the object marker results into definite reading. The example from Kihung'an in (12) is illustrative.

(12) a. Kipese ka-swiim-in kit zoon Kipese SM-buy-PST chair yesterday 'Kipese bought a chair yesterday.'

\section{b. Kipese ka-ki-swiim-in kit zoon Kipese SM-OM-buy-PST chair yesterday 'Kipese bought the chair yesterday.'}

(Morimoto, 2002:298)

These examples from different languages suggest that signalling of definiteness through object markers is a phenomenon that is not limited to Chiyao, but is widespread across Bantu languages.

\subsection{Morphosyntactic expression of definiteness}

Morphosyntactic expression of definiteness involves modification of a noun by a nominal dependent. In Chiyao, the nominal dependents that are used to signal definiteness include demonstratives, locative particles, possessive determiners, genitive expressions, and relative clauses. These strategies are detailed below. 


\subsubsection{Demonstratives}

Demonstratives can mark definiteness in quite a number of languages (Lyons, 1999). According to Van de Velde (2005), in languages that do not have articles, including Bantu languages, demonstratives perform the function similar to definite articles in languages which have articles. In this way, the demonstrative is used to refer to a referent which is identifiable to both speaker and hearer. The use of demonstratives to signal definiteness has been analysed in a number of Bantu languages, including Chaga (E62), Nyamwezi (F22), and Dciriku (K62) (Van de Velde, 2005). Like in these other languages, in Chiyao, demonstratives are important indicators of definiteness, as the examples in (13-15) below illustrate.
a. M-kologo u-jitíche
3-alcohol 3SM-be spilt
'Alcohol has been spilt.'
b. M-kologo úla u-jitíche
3-alcohol 3.DEM.DIST. 3SM-be spilt
'That/the alcohol has been spilt.'

(14) a. M-ka-jigále li-jela

1SM-FUT-take 5-hoe

'Go and bring a hoe.'
b. M-ka-jigále li-jela líla
1SM-FUT-take 5-hoe 5.DEM.DIST.
'Go and bring that/the hoe.'

(15) a. Anám-lendo ta-iche chákachi?

Q 1-guest FUT-arrive when

'When will a guest come?'
b. Aná m-lendo júla ta-iche chákachi?
Q 1-guest 1.DEM.DIST. FUT-arrive when
'When will that/the guest come?'

In (13-15) above, the (a) versions are indefinite as they appear without demonstratives while the (b) versions are definite due to presence of demonstratives. The demonstratives in the (b) examples indicate that the nouns that they modify are 
familiar and identifiable to the hearer and the speaker. They indicate that both the speaker and the hearer have some prior knowledge about the entities being discussed they may have either seen, heard or talked about the entity earlier.

As indicators of definiteness, demonstratives occur in various forms in response to deixis. Lyons (1999:18) describes deixis as "the property whereby some expressions relate entities talked about to contextual distinctions such as between the time or place where an utterance is taking place and other moments or places or that between the speaker, the hearer and others." The deictic distinctions made by demonstratives as definiteness markers may be spatial (related to the distance between the speaker, hearer and the referent) or temporal. Therefore, as far as deixis is concerned, definiteness can be expressed by using demonstratives in three deictic distinctions, namely proximal (closer to speaker) (16), non-proximal (closer to hearer) (17) and distal (far from both speaker and hearer) (18).

Achi $\quad$ chi-tengu
7.DEM.PROX
7-chair
'This chair (near me, speaker)'
Acho
chi-tengu cho
7.DEM.NON_PROX 7-chair
PART
'That chair (near you, hearer)'
Achila
chi-tengu chila
7.DEM.DIST 7-chair PART
'That chair (far from both of us)'

The NPs in the examples above are all definite as they are modified by demonstratives. The spatial deictic nature of the demonstratives used indicates that the referents are within the speakers and hearer's visibility. Since the referents are visible, the utterances in the examples above may be accompanied by gestures such as pointing to specific entities intended by the speaker.

It is important to note that, unlike the sentences in example (13-15), which contain single demonstratives each, the examples in (16-18) contain a pre-nominal and post-nominal demonstrative each. The pre-nominal demonstrative occurs in full while the post-nominal demonstrative occurs in a reduced form as a particle. The single and double occurrence of demonstratives illustrated in these two sets of examples triggers different interpretations. While in (13-15) the referents may be away from interlocutors' visibility, in (16-18) the referents are within interlocutors' visibility. It seems to suggest that demonstrative doubling is related to deictic definite NPs as in (16-18) while single 
occurrence of demonstratives is associated with anaphoric reference as in (13-15). In anaphoric reference, demonstratives are used to refer to an entity with which the hearer is familiar not from the physical situation but the linguistic context. The hearer is familiar with the entity because of its earlier mention in the text or discourse. Example (19) further illustrates the anaphoric use of demonstratives in Chiyao.

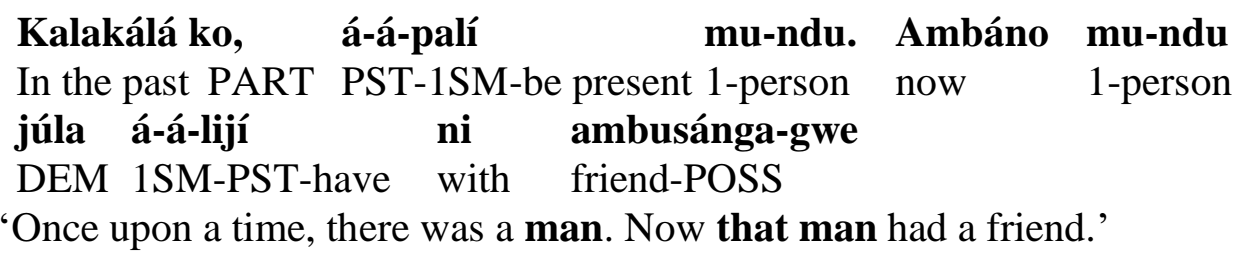

Therefore, in example (19) above the NP mundu júla 'that man' in the second sentence occurs with the demonstrative to show that it is definite since it has earlier been introduced in the first sentence in the same discourse. Since it was mentioned earlier, the referent is already familiar to the hearer in the second mention.

\subsubsection{Locative particles}

Locative particles are shortened forms of locative nouns which correspond with locative noun classes $16(\mathrm{pa}-), 17(\mathrm{ku})$, and $18(\mathrm{mu}-)$. Like demonstratives, locative particles occur in both pre-nominal and post-nominal positions, and they change their form in response to three deictic distinctions, namely proximal, non-proximal and distal as shown in Table 1 below.

\section{Table 1: Locative particles and their deictic distinctions}

\begin{tabular}{|l|l|l|l|}
\hline Class & \multicolumn{4}{|l|}{ Locative particle } \\
\hline & Proximal & Non-proximal & Distal \\
\hline 16 & pa & po & pala \\
\hline 17 & $\mathrm{ku}$ & ko & kula \\
\hline 18 & $\mathrm{mu}$ & mo & mula \\
\hline
\end{tabular}

Locative particles are an important resource for expressing anaphoric reference. As pointed out earlier, this aspect of definiteness involves a hearer identifying a referent based on discourse context clues. Using discourse particles, attention is paid by a speaker to the location which has been introduced earlier in the same discourse. The locative particle then helps the hearer to recollect the location where the event being reported in the conversation or text is taking place. 
The use of locative particles to express definiteness is very common in narrative discourses where the narrator would introduce the story and the location at which the rest of the story will be unfolding. Thus, in all the subsequent events in the story, the listener will be made to refer back to the location introduced earlier in the story through the locative particle. The listener can now effortlessly identify the location since it has already been mentioned in the story. Below is an example from a story.

$\begin{array}{lllll}\text { Kalakala } & \text { cha-apali } & \text { chi-jiji. } & \text { Pepala } & \text { pa-chi-jiji } \\ \text { In the past } & \text { 7SM.PST-exist } & \text { 7-village } & \text { 16.DEM.DIST } & \text { 16LOC-7-village } \\ \text { pala } & \text { pa-liji } & \text { ni } & \text { mw-eenye } & \\ \text { 16.PART } & \text { 16LOC-exist.PST } & \text { Assoc. } & \text { 1-chief } & \\ \text { 'Once upon a time, there was a village. In that village there was a chief.' }\end{array}$

In the above extract, the locative expressions and locative particles function anaphorically to maintain the addressee's attention on the subject which has been earlier introduced in the discourse. The location of the events in the story is chijiji 'village' which is introduced in the first sentence of the text. In the second sentence, reference to this location is made by affixing a class 16 locative prefix (pa-) to the noun chijiji 'village' and then modifying it with a locative particle of the same class pala 'there'. This is done because the location is already familiar to the addressee. Apparently, the locative particle cannot occur with the noun if it is mentioned for the first time in the discourse.

\subsubsection{Possessive determiners}

In Chiyao, a possessive determiner induces a definite interpretation of the noun it modifies. Nouns modified by possessives are definite because they refer to specific entities which both speaker and hearer can identify. The possessive determiners used in Chiyao are presented in Table 2 below.

Table 2: Possessive determiners

\begin{tabular}{|l|l|l|l|}
\hline & $\mathbf{1}^{\text {st }}$ person & $\mathbf{2}^{\text {nd }}$ person & $\mathbf{3}^{\text {rd }}$ person \\
\hline SG & -angu & -enu & - ao \\
\hline PL & -etu & -enu & $-a o$ \\
\hline
\end{tabular}

Examples (21) and (22) below provide sentential illustrations of the possessives in Table 2 above. 


\section{(21) Chi-pula changu chi-temeche}

7-knife POSS 7SM-break.PFV

'My knife is broken.'

$$
\begin{array}{lll}
\text { Nyumba jao } & \text { ji-pile } & \text { moto } \\
\text { 9.house POSS 9-SM-burn } & \text { fire } \\
\text { 'His/their house has been burnt.' }
\end{array}
$$

The possessives changu in example (21) and jao in example (22) make the nouns that they modify definite since they function to specify whose knife and whose house is being described in the verb respectively. The utterance in (21) may be given in a situation where the hearer has not seen the speaker's knife or does not even know that the speaker has a knife but will be able to realize that the knife in question is the speaker's knife and not any other knife. Similarly, the utterance in (22) informs the hearer that the house in question is not any house; it is the house belonging to a specific individual who is probably known by both speaker and hearer.

\subsubsection{Genitive expressions}

In addition to the use of possessive determiners illustrated in 4.2.3 above, possession in Chiyao can be expressed through the use of genitive forms equivalent to the English phrases such as John's and My uncle's. These are regarded as full NPs. In Chiyao, the genitive expression occurs to the right of the head noun in the form of an associative phrase which is introduced by an associative marker $-a$. Following Lyons' (1999:24) discussion of the position of genitives in relation to their head nouns, Chiyao falls under the category of Adjectival-Genitive (AD) languages ${ }^{2}$. The associative marker must be prefixed with an appropriate noun class agreement marker, as demonstrated in (23):

$\begin{array}{lll}\text { M-kutáno wá } & \text { í-nyama } \\ \text { 3-meeting } & \text { 3.Assoc. } & \text { 8-animal } \\ \text { 'Animals' meeting.' } & \end{array}$
b. Va-tumishi va misheni ja UMCA
2-worker 2.Assoc. 9.mission 9.Assoc. UMCA
'UMCA mission workers.'

\footnotetext{
${ }^{2}$ In AD languages, possessives appear in adjectival position. This contrasts with DeterminerGenitive (DG) languages in which possessives appear in a position reserved for the definite article and other definite determiners (Lyons, 1999:24).
} 


\section{c. M-gunda wa mw-eénye \\ 3.farm 3.Assoc. 1-chief \\ 'Chief's farm.'}

The addition of possessive expressions in the examples above makes their matrix noun phrases definite. In (23a), the possessive construction wa inyama 'of animals' clearly tells the hearer that the meeting in question is not any meeting but it is the one that belongs to animals. Likewise, the possessive va misheni ja UMCA 'of UMCA mission' in (23b) shows that the topic is not any workers, but workers of the UMCA mission. The possessive expression wa mweenye 'of the chief' $(23 \mathrm{c})$ specifies that the farm in question is the one that belongs to the chief, not any other farm.

Following Lyons (1999), even though the English translations of the above examples do not begin with any definite articles, they are still definite because when paraphrased, the definite article must be used before the head noun (possessor) which then results into a definite reading of the matrix noun phrase. Thus, (23a-c) can be paraphrased as 'the meeting belonging to animals', 'the missionary workers belonging to UMCA', and 'the farm belonging to a chief', respectively. Their paraphrases cannot result into indefinite NPs such as 'a meeting belonging to animals', 'any missionary workers belonging to UMCA', and 'a farm belonging to a chief', respectively. This analysis is consistent with Lyons' (1999:23) conclusion that in some languages, such as English, a possessive noun phrase, whether itself definite or indefinite, renders its matrix noun phrase definite.

\subsubsection{Nominal modification by a relative clause}

In Chiyao, definiteness of the NP can be signalled by modification of the head noun by a relative clause. The relative clause with a definite reading provides information that specifically applies to the head noun and distinguishes it from other members of its class. The target of relativisation can be either the subject (24b) or the object NP (24c). Both (24b) and (24c) are derived from the basic sentence in (24a).
a. Mw-anache a-jiv-ile ma-kaka
1-child SM1-steal-PST 6-dried cassava
'A/the child stole dried cassava.'
b. Mw-anache jw-a-jilivile ma-kaka a-utwiche 1-child REL-SM1-steal-PST 6-dried cassava SM1-escape.PFV 'The child who stole dried cassava has escaped.'




\section{c. Ma-kaka ga-a-jivile mw-anache ga-woneche 6-dried cassava REL-SM6-steal-PST 1-child SM6-be found 'The dried cassava that the child stole has been seized.'}

In (24b) above, the relative clause informs the hearer that the child being reported is not any child, but a child with some specific characteristics (i.e. stealing dried cassava) which distinguish him/her from other children in a given pragmatic context. Similarly, in (24c), the relative clause modifying the object noun denotes that the referent of the NP is not any cassava but a specific cassava with the features articulated in the relative clause (i.e. being stolen by the child). Therefore, relative clauses make the nouns they modify definite by providing extra descriptions of their referents to show that they have something specific that makes them distinct from other entities of their class. By so doing, the relative clauses also help to make the nouns familiar to the hearer.

The relativised NP in subject or object position may further be modified by a demonstrative particle to further emphasize the definite reading as in (25) below:
a. Mw-anache jw-a-jilivile
ma-kaka jula
1-child REL-SM1-steal.PST 6-dried cassava 1.DEM
a-utwiche
SM1-escape.PFV.
'That/the child who stole dried cassava has escaped.'
b. Ma-kaka ga-a-jivile mw-anache gala
ga-woneche
SM6-be found
'That/the dried cassava that the child stole has been seized.'
6-dried cassava REL-SM6-steal-PST 1-child 6.DEM

The use of the demonstrative in the relative clause demonstrated in (25) above indicates shared knowledge or awareness of the referent among interlocutors. The demonstrative helps to show that even though the referent is not within the interlocutors' visibility, they share some knowledge about it; maybe it was mentioned earlier in the discourse or conversation. As Bokamba (1971) argues, in constructions containing NPs modified by relative clauses, a speaker presupposes the truth value of an embedded relative clause, and therefore the referentiality of the matrix sentence subject. This analysis is consistent with Lyons' (1999) observation that a definite NP indicates that both the speaker and hearer are aware of the entity being referred to by 
the NP.

Signalling of definiteness through relative clauses has also been attested in other Bantu languages such as Dzamba (Bokamba, 1971) and Runyankore-Rukiga (Asiimwe 2014). However, unlike in Chiyao, in these languages, in order for a relative clause to induce a definite reading of the head noun, the relative clause must further be modified by affixing an initial vowel in the head noun or verb. Moreover, unlike Dzamba where NPs modified by relative clauses are obligatorily definite (Bokamba, 1971:227), in Chiyao, not all relativised NPs are definite. Some relativised NPs do not have a definite reading, as in (26) below:
Jwa-ngali
ma-vengwa a-ka-ika
ku-li-kwata ko
SM-not having 6-horn
SM-FUT.NEG-come 17LOC-6-dance LOC
'Anyone who does not have horns should not come to the party.'

The subject of the matrix clause in (26) above does not refer to an entity that is familiar to both interlocutors, nor does it refer to an entity that both can identify. Rather it refers to 'anyone' who does not have horns. It is therefore indefinite. Thus, the subject of a matrix clause in relativised constructions in Chiyao does not have to be always definite.

\subsection{Bare definiteness}

Bare definiteness is achieved without any morphological marking of the definite NP, nor is it syntactically modified. In Chiyao, this is evident in nouns of inalienable possession.

\subsection{Nouns of inalienable possession}

Inalienable possession is a type of possession that involves a 'possessum' which is more intimately or intrinsically tied to the possessor (Lyons, 1999:128). Nouns of inalienable possession include body parts and family relations. These nouns are interpreted as definite even without modification with a possessive affix or pronoun. This is because they denote an entity which is easily identifiable by the hearer, as shown in (27).

(27) a. Mbula ji-ku-m-beteka

9.nose 9SM-PRS-OM-pain

'(My) nose pains me.' 
$\begin{array}{lll}\text { b. Mw-anache a-temeche lu-kongolo } & \\ \text { 1-child } & \text { 1SM-break.PFV 11-leg }\end{array}$

'The child has his leg broken.'

c. Ambuje a-ku-lwala

grandfather 1SM-PRS-be sick

'(My) grandfather is sick.'

In all the examples above the NPs appear without any modifications but they are definite. When (27a) is uttered, the hearer will obviously understand that it is the speaker's nose which is in pain and not any other person's nose. Similarly, in (27b), the broken leg is clearly identified as the child's leg. In (27c) the sick grandfather is doubtlessly the grandfather of the speaker. Mojapelo (2007:126) is of the view that nouns of inalienable possession such as those presented in (27) above are definite because of the feature of locatability, which makes them identifiable. This is in line with Hawkins' (1978) location theory, which assumes that the referent of a definite noun phrase should be locatable in a shared set.

Lyons (1999) observed that in some languages, inalienable possessions undergo a possessive reduction which results into a closer integration of the possessive with the head noun. In Swahili, for example, the possessive mwenzi wako (companion your) 'your companion' is reduced to mwenzio (Lyons, 1999:128). Similar forms of inalienable possessives are attested in Chiyao with a definite sense as shown in (28-29).

(28) a. Jwamkwa jwangu (Full inalienable possession) wife my

'My wife'

b. Jwankwangu (Reduced inalienable possession)

'My wife'

(29) a. Mw-ana jwangu (Full inalienable possession)

1-child my

'My child'

b. Mwanangu (Reduced inalienable possession)

'My child'

Examples (28a) and (29a) illustrate full inalienable possession while (28b) and (29b) demonstrate reduced inalienable possession. All the examples take the 
interpretation that the head nouns (the possessa) are the speakers, and not any other person.

\subsection{Conclusion}

This paper has explored different strategies for expressing definiteness in Chiyao, a Bantu language. Three main methods of expressing definiteness in this language have been established, namely the morphological method, the morphosyntactic method, and the use of bare nouns. It has been indicated that morphological indicators of definiteness include subject and object markers while the morphosyntactic indicators include demonstratives, locative particles, possessive determiners, genitive expressions, and relative clauses. The findings have further shown that definiteness can be expressed with bare nouns, as in nouns of inalienable possession such as body parts and some kinship terms. Generally, this study suggests that although some strategies of expressing definiteness are widespread across Bantu languages, the morphosyntactic structure of a given language highly determines which method to employ. For example, it is not possible for Chiyao to use nominal pre-prefixes to express definiteness since the structure of this language does not permit the use of such elements.

\section{References}

Allen, Keith. 1983. "Anaphora, Cataphora, and Topic Focusing, Functions of the Object Prefix in Swahili." In Current Approaches to African Linguistics1, edited by Ivan Dihoff, 323-336. Dordrecht: Foris.

Asiimwe, Allen. 2014. Definiteness and Specificity in Runyankore-Rukiga. Doctoral Dissertation. Stellenbosch University.

Bokamba, Eyamba. 1976. Question Formation in some Bantu Languages. Ph.D Thesis. Indiana University.

Bokamba, Eyamba. 1979. "Inversions as Grammatical Relation Changing Rules in Bantu Languages." Studies in the Linguistic Sciences 9: 1-24.

Bokamba, Georges.1971. "Specificity and Definiteness in Dzamba." Studies in African Linguistics 2: 217-238.

Bresnan, Joan and Sam Mchombo. 1987. "Topic, Pronoun, and Agreement in Chichewa. Language 63(4): 741-782.

Bresnan, Joan and Lioba Moshi. 1993. "Object Asymmetries in Comparative Bantu Syntax." In Theoretical Aspects of Bantu Grammar, edited by Sam Mchombo, 4791. Stanford, CA: CSLI Publications.

Byarushengo, Ernest and Sarah Tenenbaum. 1976. "Agreement and Word Order: A Case of Pragmatics in Haya." In Proceedings of the $2^{\text {nd }}$ Annual Meeting of the 
Berkeley Linguistics Society, 89-99.

Christophersen, Paul. 1939. The Articles: A Study of their Theory and Use in English. Copenhagen: Munksgaard.

Demuth, Katherine and Carolyn Harford. 1999. "Verb Raising and Subject Inversion in Bantu Relatives." Journal of African Languages and Linguistics 20: 41-61.

Demuth, Katherine and Sheila Mmusi. 1997. "Presentational Focus and Thematic Structure in Comparative Bantu." Journal of African Languages and Linguistics 18: $1-19$.

Duarte, Fábio. 2011. "Tense Encoding, Agreement Patterns, Definiteness and Relativisation Strategies in Changana." In Selected Proceedings of the $4^{\text {th }}$ Annual Conference on African Linguistics, edited by Eyamba G. Bokamba, Ryan K. Shosted and Bezza T. Ayalew, 80-94. Somerville, M.A: Cascadilla Proceedings Project.

Givón, Talmy. 1978. "Definiteness and Referentiality." In Universals of Human Language 4, edited by Joseph H. Greenberg, Charles A. Ferguson and Edith A. Moravcsik, 292-330. Stanford: Stanford University Press.

Guthrie, Malcolm. 1948. The Classification of Bantu Languages. London: Oxford University Press.

Hawkins, John. 1978. Definiteness and Indefiniteness: A Study in Reference and Grammaticality Prediction. London: Croon Helm.

Heim, Irene. 1982. Semantics of Definite and Indefinite Noun Phrases. Amherst: University of Massachusetts.

Karttunen, Lauri. 1968. "What Makes Definite Noun Phrases Definite.” RAND Corporation Report No. P3871: The RAND Corporation.

Kidima, Lukowa. 1987. "Object Agreement and Topicality Hierarchies in Kiyaka." Studies in African Linguistics 18: 175-209.

Kimambo, Gerald. 2018. "The Morpho-syntactic and Semantic-pragmatic Realisation of Definiteness and Specificity in Swahili." Ghana Journal of Linguistics 7(1): 65-83.

Lambrecht, Knud. 1996. Information Structure and Sentence Form: Topic, Focus and Mental Representations of Discourse Referents. Cambridge: Cambridge University Press.

Lyons, Christopher. 1999. Definiteness. Cambridge: Cambridge University Press.

Machobane, Malillo. 1987. "The Sesotho Passive Constructions." McGill Working Papers in Linguistics 4(2): 33-52. Montreal: McGill University.

Mojapelo, Mampaka. 2007. Definiteness in Northern Sotho. Doctoral Thesis. Stellenbosch University.

Morimoto, Yukiko. 2002. "Prominence Mismatches and Differential Object Marking in Bantu." In Proceedings of the LFG02 Conference, edited by Miriam Butt and 
Tracy Holloway King, 292-314. CSLI Publications.

Nurse, Derek and Gérard Philippson. 1980. "The Bantu Languages of East Africa: A Lexicostatistical Survey." In Language in Tanzania, edited by Edgar. C. Polome and C.P. Hill, 26-67. London: Oxford University Press for the International African Institute.

Seidl, Amanda and Alexis Dimitriadis. 1997. "The Discourse Function of Object Marking in Swahili. CLS 33 : 373-389.

Van de Velde, Mark. 2005. "The Order of Noun and Demonstrative in Bantu." In Studies in African comparative linguistics with special focus on Bantu and Mande, edited by Koen Bostoen and Jacky Maniacky, 425-441. Tervuren: Royal Museum for Central Africa.

Visser, Marianna. 2008. "Definiteness and Specificity in the isiXhosa Determiner Phrase." South African Journal of African Languages 1: 11-29.

Wald, Benji. 1973. "Syntactic Change in the Lake Languages Northeast Bantu." Studies in African Linguistics 4(3): 237-268.

Wald, Benji. 1979. "The Development of the Swahili Object Marker: A Study of the Interaction of Syntax and Discourse." In Discourse and Syntax 12, edited by Talmy Givón, 505-524. New York: Academic Press.

Zerbian, Sabine. 2007. "Investigating Prosodic Focus in Northern Sotho.” In Focus Strategies in African Languages, edited by Enoch. O. Aboh, Katharina Harmann and Malte Zimmerman, 55-79. Berlin: Mouton de Gruyter. 